Check for updates

Cite this: Mater. Chem. Front., 2019, 3, 1823

\title{
A novel family of AIE-active meso-2-ketopyrrolyl BODIPYs: bright solid-state red fluorescence, morphological properties and application as viscosimeters in live cells $\dagger$
}

\author{
Changjiang Yu, (D) $\ddagger^{\text {abc }}$ Zhenlong Huang, $\ddagger^{d}$ Wei Gu, ${ }^{a}$ Qinghua Wu, ${ }^{a}$ Erhong Hao, (D) *a \\ Yi Xiao, (D)*d Lijuan Jiao (D) *a and Wai-Yeung Wong (D)*b
}

\begin{abstract}
Fluorescent probes towards viscosity determination can be used to report on variations in local molecular viscosity and have become valuable tools for the study of intracellular microenvironments. Herein, we develop a family of remarkable meso-2-ketopyrrolyl-derived BODIPY rotors and report a new strategy for building them via simple condensation reactions between oxalyl chloride and substituted pyrroles. They are well characterized by NMR, HRMS, crystal structure, spectroscopic and morphological studies. These uncommon meso-2-ketopyrrolyl-derived BODIPYs are weakly fluorescent in their organic solutions but exhibit bright solid-state red fluorescence from 620 to $661 \mathrm{~nm}$ with a maximum fluorescence quantum yield of $25 \%$. All of them also exhibit notable aggregation-induced emission (AIE)-active features. Interestingly, the formed nanoaggregates were observed to exhibit morphological distinctions owing to different substituents. The fluorescence enhancement towards the increased viscosity of the environment might be mainly attributed to the restriction of their intramolecular rotations of the meso-ketopyrrolyl groups. More interestingly, the increase in the fluorescence lifetime of these representative rotors appears to perfectly correlate with the increase in the viscosity of the media, and they have been used as viscosimeters for real-time quantitative determination of the variation of the intracellular viscosity in live cells. The easy synthetic strategy and real-time quantitative determination of the variation pave a new way for creating fluorescent molecular rotor materials.
\end{abstract}

Received 13th March 2019,

Accepted 25th June 2019

DOI: 10.1039/c9qm00154a

rsc.li/frontiers-materials

\section{Introduction}

Intracellular micro-viscosity has a very important role in the study of multifarious signal transportation and cellular processes such as reticulophagy and division/death of cells. ${ }^{1}$ Among various strategies for measuring viscosity directly, membrane permeable fluorescent molecular rotors (FMRs) that are sensitive to the

\footnotetext{
${ }^{a}$ The Key Laboratory of Functional Molecular Solids, Ministry of Education, Anhui Laboratory of Molecule-Based Materials (State Key Laboratory Cultivation Base), School of Chemistry and Materials Science, Anhui Normal University, Wuhu, China.E-mail: haoehong@ahnu.edu.cn, jiao421@ahnu.edu.cn

${ }^{b}$ Department of Applied Biology and Chemical Technology, The Hong Kong Polytechnic University, Hung Hom, Kowloon, Hong Kong, China. E-mail: wai-yeung.wong@polyu.edu.hk

${ }^{c}$ State Key Laboratory of Coordination Chemistry, Nanjing University, Nanjing 210093, China

${ }^{d}$ State Key Laboratory of Fine Chemicals, Dalian University of Technology, 2 Linggong Road, Dalian 116024, China. E-mail:xiaoyi@dlut.edu.cn $\dagger$ Electronic supplementary information (ESI) available: Fig. S1-S31 and Tables S1-S4. CCDC 1541729, 1541728 and 1901461 for 1a-c. For ESI and crystallographic data in CIF or other electronic format see DOI: 10.1039/c9qm00154a \$ C. Y. and Z. H. contributed equally.
}

viscosity of the surrounding microenvironments have been regarded as a class of the most successful probes for intracellular viscosity. ${ }^{2,3}$ The developed rotors suitable for fluorescence intensity or fluorescence lifetime imaging techniques usually undergo molecular rotation and further effectively dissipate their excitation energies. The corresponding fluorescence signals could be used to directly report the variations in local molecular viscosity, especially for some abnormal changes, which are closely associated with many diseases and pathologies including diabetes and Alzheimer's disease. $^{4}$

Recently, some elegant FMRs based on fluorescent BODIPY (boron dipyrromethene) ${ }^{5}$ segments have been developed due to their high fluorescence quantum yields and the high rotational ability of the substituents at the meso-position, giving a linear correlation between their fluorescence lifetime and viscosity, and widely applied as viscosity sensors in intracellular microenvironments in fluorescence lifetime imaging microscopy (FLIM) techniques. ${ }^{1 d, 6-11}$ However, most of the recently developed BODIPY-based FMRs almost have similar cores of meso-phenyl substituted BODIPYs. ${ }^{1 b, 6-10}$ The efficient strategy for these BODIPY FMRs is based on the rotation of the meso-phenyl 
group around a $\mathrm{C}-\mathrm{C}$ single bond, which causes a non-radiative decay in the excited state in non-viscous media. ${ }^{9}$ An increase of viscosity makes it more difficult to rotate the meso-phenyl group. This inhibits the non-radiative decay process and brings an increase of fluorescence lifetime. Using this strategy, one group of us previously developed a BODIPY-based FMR for high temporal and spatial determination of lysosomal viscosity in living cells through FLIM. $^{10}$ Different from conventional BODIPY-based FMRs, only one example of BODIPY B distorted from internal steric hindrance between the 1,7-dimethyl group and the meso-CHO was found as an impactful viscosimeter in 2014 by Fan and Peng. ${ }^{11}$ Nevertheless, despite some advantages, BODIPY dyes exhibit some drawbacks such as low fluorescence quantum yields in the solid state and relatively complicated syntheses. Based on the above studies, we rationalized that a less bulky group such as 2-ketopyrrolyl (than phenyl) at the meso-position of a BODIPY at the same time together with the 1,7-dimethyl group may allow its rotation in non-viscous media. This kind of BODIPY dye might show bright solid-state emission and provide an alternative strategy for synthesizing novel unconventional and efficient viscosity probes.

Herein, we develop a new strategy for building uncommon meso-2-ketopyrrolyl BODIPY derivatives containing the 1,7-dimethyl group (Fig. 1), which exhibit great performance comparable or even superior to those of conventional BODIPY-based FMRs. Firstly, the easy synthetic method of the two meso-2-ketopyrrole derived BODIPYs has been reported for the first time via simple condensation between commercial oxalyl chloride and pyrrole derivatives. Secondly, these rotors unexpectedly showed notable aggregation-induced emission (AIE) features and bright red fluorescence in the solid state. Thirdly, their fluorescence intensity and lifetime were observed to perfectly correlate with the viscosity of the medium. The real-time determination of the variation of the viscosity in live cells by using FLIM has been successfully demonstrated, which qualifies them as a novel class of BODIPY-derived molecular rotors.

\section{Results and discussion}

\subsection{Synthesis and characterization}

Initially, the desired meso-2-ketopyrrolyl BODIPY 1a was synthesized by the condensation of oxalyl chloride with a stoichiometric amount of 2,4-dimethyl-3-ethylpyrrole, and a subsequent $\mathrm{BF}_{2}$ complexation under refluxing conditions (Scheme 1), which

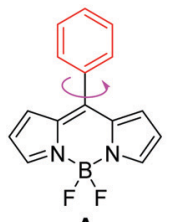

A

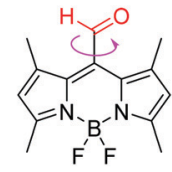

B

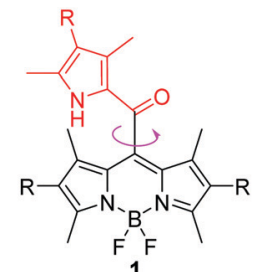

Fig. 1 The chemical structures of FMRs: conventional meso-phenyl derived BODIPY A, meso-aldehyde derived BODIPY $\mathbf{B}$ and our designed meso-2-ketopyrrolyl BODIPYs $\mathbf{1}$ in this contribution. was confirmed by single crystal X-ray crystallography. Interestingly, similar condensation of oxalyl chloride with 2 eq. of 2,4-dimethyl-3ethylpyrrole at room temperature by Akkaya and coworkers gave unexpected two difluoroboron chelated oxalyl-tethered pyrroles. ${ }^{12}$ The reaction conditions were then optimized and we found that 3.5 eq. of 2,4-dimethyl-3-ethylpyrrole was enough for obtaining the targeted meso-2-ketopyrrolyl derived BODIPY 1a. Under the optimized conditions, the desired meso-2-ketopyrrolyl substituted BODIPYs 1a and 1b were synthesized from the corresponding pyrroles in one pot in $18 \%$ and $23 \%$ yields, respectively. Dipyrrolyldiketones $\mathbf{2 a - b}$ prepared from oxalyl chloride and substituted pyrroles $^{13}$ were then found to succeed in condensing with another pyrrole molecule under $\mathrm{BF}_{3} \cdot \mathrm{OEt}_{2}$, respectively, followed by the complexation with $\mathrm{BF}_{3} \cdot \mathrm{OEt}_{2}$ in the presence of triethylamine (Scheme 1), from which the targeted meso-2-ketopyrrolyl BODIPYs 1a-d were prepared in $32-45 \%$ yields. The chemical shifts $\delta$ of meso-uncoordinated pyrrolic $\beta-\mathrm{H}$ at $5.84 \mathrm{ppm}$ for 1b and 1d, respectively, revealed much higher fields than those of coordinated pyrrolic $\beta-\mathrm{H}$. These meso-2-ketopyrrolyl BODIPYs were well characterized by ${ }^{1} \mathrm{H}$ and ${ }^{13} \mathrm{C}$ NMR and HRMS. Their structures were further confirmed by single crystal X-ray crystallography. Several meso-ester BODIPYs have been reported; ${ }^{14}$ however, the synthesis of meso-ketone derived BODIPYs has not been previously developed. Our method developed here provides a facile access to these novel BODIPYs of this kind for the first time. More interestingly, Bae and Kim demonstrated a fluorogenic J-aggregating meso-ester BODIPY recently, which could selectively monitor and image eosinophil peroxidase activity. ${ }^{14 e}$

\subsection{X-ray crystallography}

The crystal structure plots for the meso-2-ketopyrrolyl derived BODIPYs 1a-c are given in Fig. 2 and Fig. S1-S3 in the ESI $\dagger$ and the crystal data are listed in Tables S1 and S2 (ESI $\dagger$ ). They all belong to the monoclinic space group $C 2 / c$ and their boron atoms show a tetrahedral structure. The average $\mathrm{B}-\mathrm{N}$ distances for $\mathbf{1 a}-\mathbf{b}$ are almost the same (1.54 $\AA$ for $\mathbf{1 a}$ and $1.55 \AA$ for $\mathbf{1 b})$, supporting their symmetrical structures. In sharp contrast to them, the average $\mathrm{B}-\mathrm{N}$ distances of $1 \mathrm{c}$ are 1.53 and $1.55 \AA$, confirming the unsymmetrical structures of $1 \mathrm{c}$ and $\mathbf{1 d}$. What deserves to be mentioned is that the dipyrrin cores of these novel meso-2-ketopyrrolyl BODIPYs are planar, which is similar to previously reported $\mathrm{BF}_{2}$ complexes, ${ }^{15}$ and the dihedral angles defined by two coordinated pyrrolic rings are $5.0^{\circ}, 8.8^{\circ}$ and $1.5^{\circ}$ (Table S1, ESI $\dagger$ ) for $\mathbf{1 a - c}$, respectively. This indicates that the
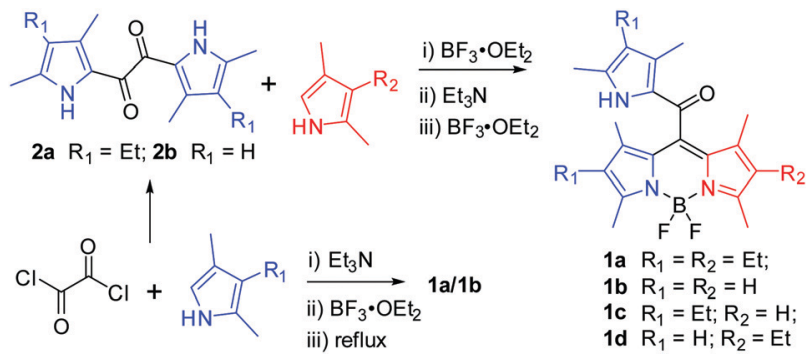

Scheme 1 Syntheses of meso-2-ketopyrrolyl BODIPYs 1a-d 


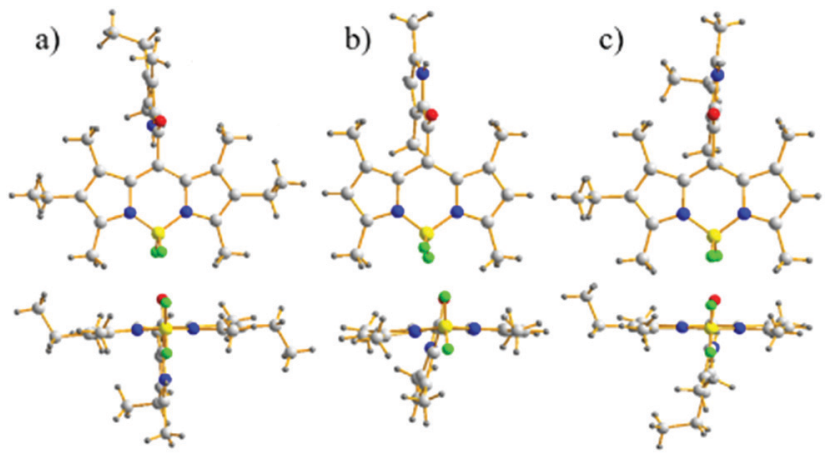

Fig. 2 Front and top views of the $\mathrm{X}$-ray structures for meso-2ketopyrrolyl BODIPYs 1a-c. C, light gray; $\mathrm{H}$, gray; $\mathrm{N}$, blue; $\mathrm{F}$, bright green; $B$, yellow; O, red.

installation of a steric meso-2-ketopyrrolyl substituent into the BODIPY core causes negligible structural distortion of the planarity of the BODIPY core structure. The carbonyl group as a linker avoided internal steric hindrance between the BODIPY core and the uncoordinated pyrrole ring at the meso-position. The results are quite different from the "distorted BODIPY" $\mathbf{B}$, although they both have the same 1,7-dimethyl group and the carbonyl group. The carbonyl group and the uncoordinated pyrrole ring in their crystals are coplanar. In addition, the dihedral angles defined by the meso-2-ketopyrrolyl moiety and the BODIPY core are $88.8^{\circ}, 72.9^{\circ}$ and $81.4^{\circ}$, respectively, for 1a-c (Table S1, ESI $\dagger$ ), which are almost vertical.

\subsection{Photophysical studies}

The absorption and emission spectra (Fig. 3 and Fig. S4-S9, ESI $\dagger$ ) of these meso-2-ketopyrrolyl BODIPYs $1 \mathbf{1 a}-\mathbf{d}$ were measured in various common organic solvents with different polarities such as cyclohexane, toluene, dichloromethane, tetrahydrofuran, acetonitrile and methanol (Table S3, ESI $\dagger$ ). They all exhibit a strong absorption band in the $450-550 \mathrm{~nm}$ region. For example, 1a exhibits an intense absorption band centred at $534 \mathrm{~nm}$ with a high extinction coefficient of $4.81 \times 10^{4} \mathrm{M}^{-1} \mathrm{~cm}^{-1}$ (Fig. 3a and Fig. S4, Table S3, ESI $\dagger$ ). With respect to $\mathbf{1 b}$ in dichloromethane, obvious bathochromic shifts were observed for 1a and 1c (Fig. 3a and Fig. S4 and S8, ESI $\dagger$ ). It is worth mentioning that 1c and 1d with the same unsymmetrical BODIPY core exhibit almost the same absorption and emission (Fig. S8 and S9 and Table S3, $\mathrm{ESI} \dagger)$. The results indicate that the enhancement of the intramolecular charge transfer (ICT) effect of alkyl substituents on the coordinated pyrrole ring might mainly contribute to the observed bathochromic shifts. Besides, these meso-2-ketopyrrolyl BODIPYs exhibit relatively large Stokes shifts ranging from 653 to $986 \mathrm{~cm}^{-1}$. In addition, no significant variations of the absorption and emission maxima were observed with the variation of the polarity of the organic solvents for them although a slight variation of the fluorescence intensity was observed (Table S3, ESI $\dagger$ ).

In comparison with most BODIPY dyes, ${ }^{15}$ most of these meso-2-ketopyrrolyl BODIPYs are poorly emissive in organic solvents except for 1a, which exhibit relatively much higher fluorescence quantum yields $(\phi)$ of $0.10-0.21$ (Table S3, ESI $\dagger$ ).
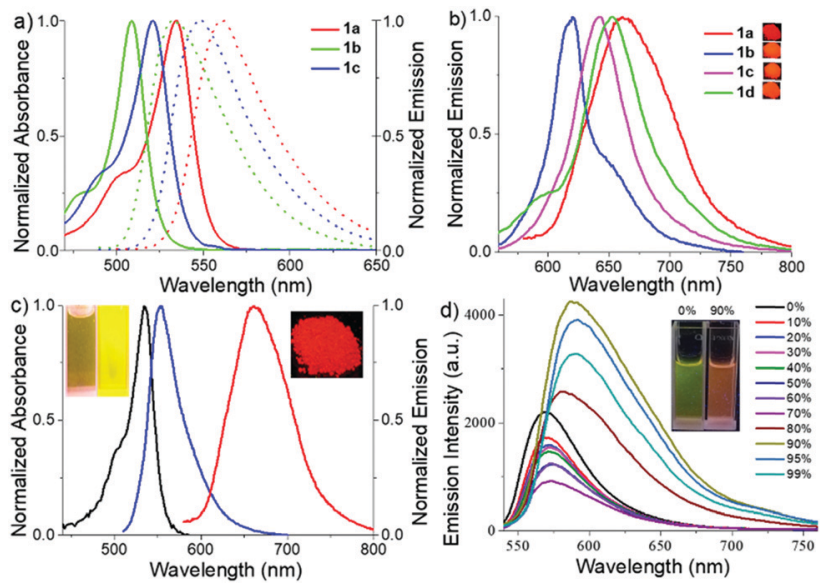

Fig. 3 (a) Overlaid normalized absorption and emission spectra of $\mathbf{1 a - c}$ in dichloromethane, excited at $480 \mathrm{~nm}$ for $\mathbf{1 a}$ and $460 \mathrm{~nm}$ for $\mathbf{1 b}$ and c. (b) Normalized emission spectra of $\mathbf{1} \mathbf{a}-\mathbf{d}$ in the powder state, excited at $550 \mathrm{~nm}$ for $\mathbf{1 a}$ and $500 \mathrm{~nm}$ for $\mathbf{1 b} \mathbf{b} \mathbf{d}$. Photographs of their powders under $365 \mathrm{~nm}$ UV lamp irradiation. (c) Normalized absorption (black) and emission (blue) spectra in glycerol, and the emission spectrum in the powder state (red) of 1a. Photographs of the samples in daylight and under $365 \mathrm{~nm}$ UV lamp irradiation. (d) Emission spectra of $\mathbf{1 a}$ in acetonitrile/water with different water fractions, excited at $500 \mathrm{~nm}$.

For example, the fluorescence quantum yields were evaluated to be 0.03 and 0.01 , respectively, for $\mathbf{1 b}$ and $\mathbf{1 c}$ in acetonitrile. The possible rotations of the meso-2-ketopyrrolyl group might result in the internal conversion through a non-radiative process. As expected, 1a and $\mathbf{1 b}$ indeed show bright fluorescence emission in glycerol, with fluorescence quantum yields of 0.43 and 0.15 , respectively (Fig. 3c and Fig. S5 and S7, Table S3, ESI $\dagger$ ). In their powder state, they exhibit relatively strong fluorescence as well. Besides, red-shifted fluorescence emissions were observed with maxima centered at 662, 620, 653 and $644 \mathrm{~nm}$, respectively, for 1a-d (Fig. 3b) and their fluorescence quantum yields range from 0.13 to 0.25 as summarized in Table S3 (ESI $\dagger$ ). The bright solidstate red-emissive properties are similar to those in a recent paper published by Niu and co-workers. ${ }^{15 f} \mathbf{1 a - c}$ exhibit characteristic J-aggregating packing as previously reported. ${ }^{14 b, 16 a}$ Their packing patterns are observed to adopt a coplanar inclined arrangement of the transition dipoles, respectively, with slip angles of $23.2^{\circ}, 30.7^{\circ}$, and $18.5^{\circ}$, and adjacent interlayer distances of $4.12 \AA$, $3.38 \AA$, and $3.88 \AA$ for 1a-c (Fig. S1-S3, $\mathrm{ESI} \dagger$ ). The head-to-head or head-to-tail dimer and J-aggregating crystal packing might inhibit the free rotation of the meso-2ketopyrrolyl group, reduce the nonradiative rate of energy loss, and further enhance their solid-state red emissive quantum yields.

To further understand the electronic properties of the meso2-ketopyrrolyl BODIPYs, the density functional theory (DFT) and time-dependent DFT (TDDFT) calculations were performed using a B3LYP/6-311++G* basis set. As can be deduced from Fig. 4, the HOMO-1 electronic distribution of $\mathbf{1 a}$ is mainly localized on the 2-ketopyrrolyl group segment, while the LUMO is delocalized over the BODIPY core, indicating an obvious ICT character. The TDDFT calculated parameter (Table S4, ESI $\dagger$ ) of BODIPY 1a shows $S_{0} \rightarrow S_{1}$ with an excitation wavelength of 


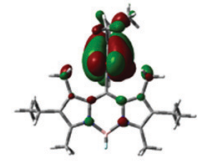

HOMO-1

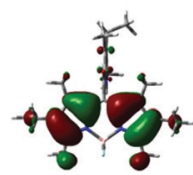

HOMO

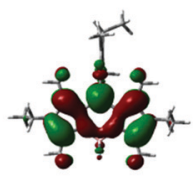

LUMO

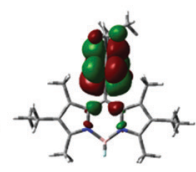

$\mathrm{LUMO}+1$
Fig. 4 Molecular frontier orbital plots of meso-2-ketopyrrolyl BODIPY 1a calculated with DFT at the B3LYP/6-31+G(d,p) level.

$468 \mathrm{~nm}$, oscillator strength $f=0.2725$; and $\mathrm{S}_{0} \rightarrow \mathrm{S}_{2}$ with an excitation wavelength of $449 \mathrm{~nm}$, oscillator strength $f=0.3296$. These two excited states may all contribute to the maximum absorption. The $\mathrm{S}_{0} \rightarrow \mathrm{S}_{1}$ energy state is fully contributed by HOMO-1 $\rightarrow$ LUMO and HOMO $\rightarrow$ LUMO (Table S4, ESI $\dagger$ ).

\subsection{AIE studies}

Encouraged by their photophysical properties as observed above, we studied their AIE behaviour by gradually increasing the water fraction from 0 to $99 \%$ in the acetonitrile-water system and measuring the variation of their absorption and fluorescence emission. With an increasing water content of over $80 \%$, their absorption spectra exhibited more broad and dual peaks (Fig. S10a, S11a, S12a and S13a, ESI $\dagger$ ), which are characteristic of the J-type packing ${ }^{14 b, 16 a}$ and possibly formed nanoparticles. As shown in Fig. 3d and Fig. S10b (ESI $\dagger$ ), 1a exhibits relatively weak emission in pure acetonitrile. However, by increasing the water fraction to $90 \%$, its fluorescence intensity increases instantaneously with the redshifted emission maximum at $591 \mathrm{~nm}$, indicating that 1a is a new AIEgen. Similarly, 1b-d also exhibited excellent AIE-activity in the aforesaid solvent system (Fig. S11b, S12b and S13b, ESI $\dagger$ ). It is worth mentioning that a further increase of the water fraction up to $99 \%$ for $\mathbf{1 b}$ and $\mathbf{1 c}$ (Fig. S11b and S12b, ESI $\dagger$ ) leads to an increase of the fluorescence intensity, while maintaining the position of their emission maxima. Their red-shifted and enhanced emissions in the aggregated state might be ascribed to their rigidified molecular structures as well as strong dipole-dipole interactions. Their fluorescence activities above revealed that they exhibit notable AIE-activity. The AIE phenomenon ${ }^{16-20}$ is very unusual for the members of the BODIPY family which normally exhibit a very strong tendency of ACQ. To our best knowledge, only very limited AIE-active BODIPYs have been reported. ${ }^{16-18}$ Some of them were elegantly designed through conjugation of BODIPY derivatives with AIE-active tetraphenylethene moieties developed by Tang. ${ }^{17}$

To make clear their aggregation behaviours, 1a-d with a water fraction of $90 \%$ in the acetonitrile-water system were, respectively, subjected to scanning electron microscopy (SEM) and transmission electron microscopy (TEM). Very interestingly, different types of nanoaggregates were formed within their solutions. As shown in Fig. 5a and Fig. S14a and b (ESI $\dagger$ ), nanoball aggregates of relatively uniform size were created for $\mathbf{1 a}, \mathbf{1 c}$ and 1d, respectively. In sharp contrast to them, $\mathbf{1 b}$ gave cuboid nanoaggregates about $200 \mathrm{~nm}$ wide (Fig. 5b). The shape and size of these aggregates are further confirmed by the corresponding TEM plots (Fig. 5c and d and Fig. S14c and d, ESI $\dagger$ ), which are in good

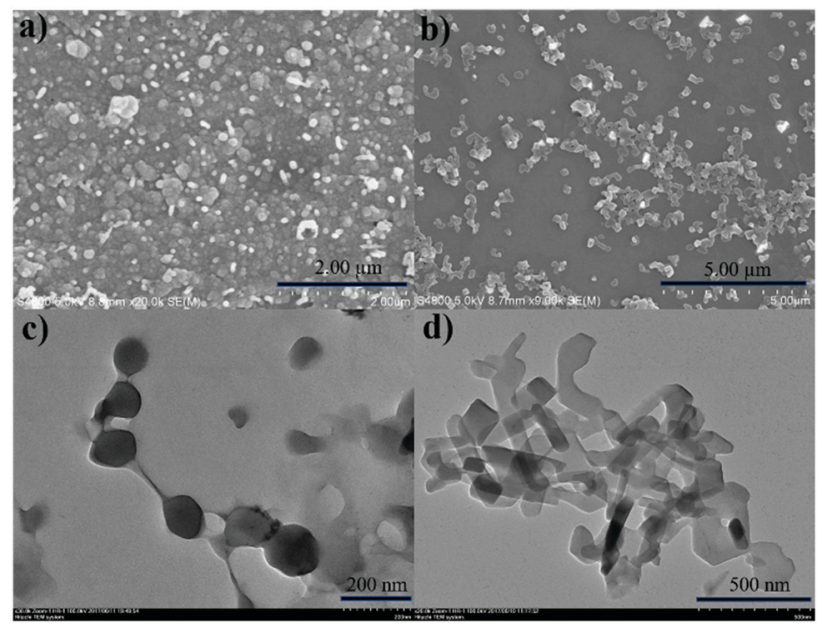

Fig. 5 SEM ( $a$ and $b)$ and TEM ( $c$ and $d$ ) images of nanoballs for $1 a(50 \mu M)$ and nanocuboids for $\mathbf{1 b}(30 \mu \mathrm{M})$ in the acetonitrile-water system containing a water fraction equal to $90 \%$. The insets show the corresponding magnified images.

agreement with SEM. Dynamic light scattering (DLS) measurements of 1a and $\mathbf{1 b}$ with the water fraction equal to $99 \%$ in the acetonitrile-water system (Fig. S15 and S16, ESI $\dagger$ ) revealed the average diameter sizes of 200 and $348 \mathrm{~nm}$ and the corresponding PDI values of 0.098 and 0.283 , respectively. Among the formed nanoaggregates, the size of the aggregates of $\mathbf{1 a}$ is smaller, which may be ascribed to its greater hydrophobicity due to its possession of more alkyl substituents. The obviously morphological distinction between nanoballs for $\mathbf{1 a}$ and nanocuboids for $\mathbf{1 b}$ indicates that their aggregate morphologies could be tunable. The observed phenomenon was similar to AIE luminogens based on quinolineBODIPYs developed by Pandey. ${ }^{18 a}$

\subsection{Viscosity studies}

To decrease the rapid non-radiative decay and restrict their rotations, we tested viscosity $(\eta)$ sensitivity for these two novel meso-2-ketopyrrolyl BODIPYs as FMRs by increasing the volume ratio of glycerol to methanol. The gradually increased viscosity restricts the motions of the meso-2-ketopyrrolyl groups, decreases their nonradiative rate of energy loss, and naturally enhances their fluorescence for 1a-d (Fig. 6a and Fig. S17-S19, $\mathrm{ESI} \dagger$ ). The gradual increase of the viscosity from 0.6 to $360 \mathrm{cP}$ brings a continuous enhancement of the fluorescence emission intensity $(F)$ of $\mathbf{1 a}$ and $\mathbf{1 b}$ at 560 and $530 \mathrm{~nm}$, respectively (Fig. 6a and Fig. S17, ESI $\dagger$ ). More importantly, we were fortunate to find that both dyes exhibited quite perfect linear relationships between their $\log \left(F / F^{\prime}\right)$ and $\log \eta$ (Pearson's $r=0.996$ for 1a, Fig. 6b; and Pearson's $r=0.990$ for $1 \mathbf{b}$, Fig. S20, ESI $\dagger$ ). In comparison with that of the fluorescence intensity, the detection of the fluorescence lifetime has more intrinsic advantages for practical applications in imaging, because the fluorescence lifetime is independent of the sample concentration and does not depend on the intensity of the laser. ${ }^{6-8}$ Thus, the fluorescence decays of these meso-2-ketopyrrolyl BODIPYs $\mathbf{1 a}$ and $\mathbf{1 b}$ in methanol/ glycerol mixtures with different viscosities were studied (Fig. 6c and Fig. S21, ESI $\dagger$ ). Similar to that observed in the increase of the 

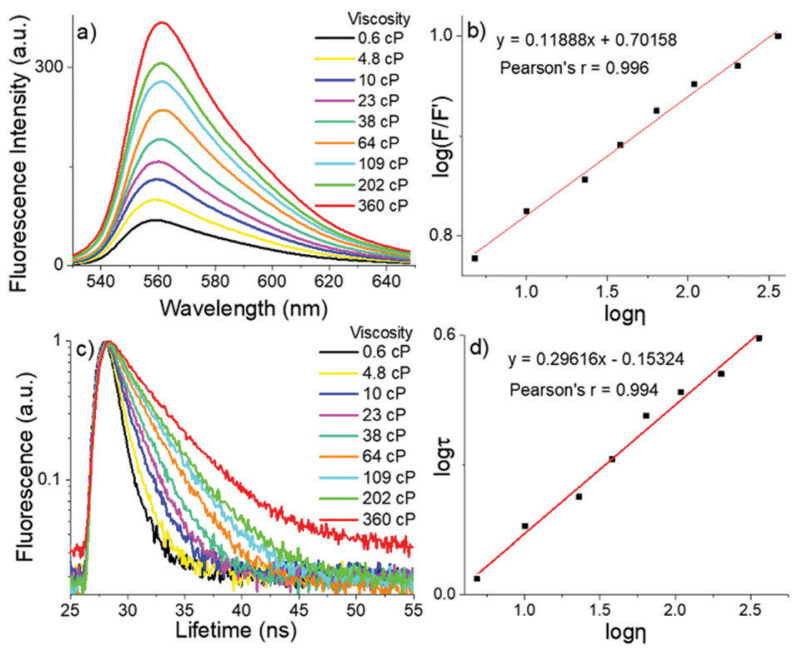

Fig. 6 (a) Fluorescence intensity of $1 \mathrm{a}(5 \mu \mathrm{M}$, excited at $500 \mathrm{~nm})$ with the variation of the viscosity of the system in the methanol-glycerol system. (b) Linear working curve between $\log \left(F / F^{\prime}\right)$ and $\log \eta$ of $1 \mathrm{a}(560 \mathrm{~nm})$ (c) Fluorescence lifetime for $1 \mathrm{a}$ with the variation of the viscosity collected at $560 \mathrm{~nm}$. (d) Linear working curve between $\log \tau$ and $\log \eta$ for 1 a.

fluorescence intensity of 1a, a remarkable increase of the fluorescence lifetime $(\tau)$ at $560 \mathrm{~nm}$ (from $0.8 \mathrm{~ns}$ to $3.9 \mathrm{~ns}$ ) was observed for $1 \mathrm{a}$ with the increase of the viscosity from $0.6 \mathrm{cP}$ to $360 \mathrm{cP}$ in methanol/glycerol solutions. In particular, a greatly perfect linear relationship was also observed between $\log \tau$ and $\log \eta$ with Pearson's $r$ of 0.994 (Fig. 6d), indicating that meso-2-ketopyrrolyl BODIPY 1a we have developed in this contribution could be used to construct calibration curves to quantitatively detect viscosity in vitro. Similar linear correlations of the fluorescence lifetimes (Fig. S22, $\mathrm{ESI} \dagger$ ) for $\mathbf{1 b}$ were also determined as a function of viscosity with Pearson's $r$ of 0.997 , respectively, indicating that $\mathbf{1 b}$ might also be used as a viscosity mapping rotor for real-time tracking viscosity changes during cell apoptosis events.

\subsection{Cell culture}

Before they were used for MTT and cellular uptake, the morphology of 1a $(5 \mu \mathrm{M})$ was studied in phosphate-buffered saline (PBS, $\mathrm{pH}=7.4)$. In distinct contrast to those at a concentration of $50 \mu \mathrm{M}$, no nanoparticles were observed for $5 \mu \mathrm{M}$ 1a (Fig. S23a, $\mathrm{ESI} \dagger$ ). As confirmed by energy dispersive X-ray spectrometer (EDS, Fig. S23, ESI $\dagger$ ) mapping, 1a was found to be dispersed in PBS. Besides, the solubility of $1 \mathrm{a}(5 \mu \mathrm{M})$ was studied in Dulbecco's modified Eagle's medium (DMEM). As shown in Fig. S24 (ESI $\dagger$ ), 1a in DMEM exhibits similar absorbances at different concentrations with the absorption wavelength maximum of $540 \mathrm{~nm}$, and the absorbance complies with the Lambert-Beer law, with $\lg \varepsilon_{\text {abs }}$ of 4.61 . The results indicated that aggregates were not formed for $5 \mu \mathrm{M} 1 \mathrm{a}$ in DMEM. The results further confirmed that these dyes were not in the aggregated-form when used for cellular uptake, and intracellular micro-viscosity might play a critical role. Membrane permeation is the most likely way for small molecule fluorescent dyes to enter the cells. To make clear if our dyes could localize subcellular organelles, the co-localization experiments were carried out. The co-localization imaging studies (Fig. S25 and S26, ESI $\dagger$ ) show

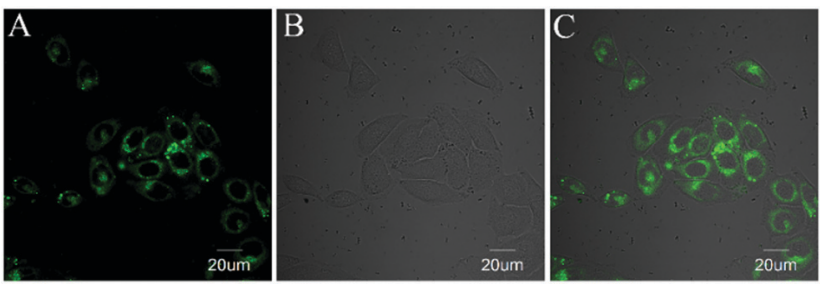

Fig. 7 Imaging of $1 \mathrm{a}$ in MCF-7 cells. (A) MCF-7 cells stained with 1a (5 $\mu \mathrm{M}$, $\lambda_{\mathrm{ex}}=515 \mathrm{~nm}, \lambda_{\mathrm{em}}=520-600 \mathrm{~nm}$ ); (B) DIC image; and (C) merge of $A$ and $B$.

that the positions of different subcellular organelles with different viscosities (like cytoplasm, lysosome and the ER) are all distributed for $\mathbf{1 a}$ and $\mathbf{1 b}$. It is precisely because these dyes are dispersed in the cytoplasm, so they can be used to detect the overall level of intracytoplasmic viscosity.

Inspired by the excellent viscosity sensitivity above for these novel meso-2-ketopyrrolyl BODIPYs, we then studied their cell imaging. After incubation with $\mathbf{1 a}$ and $\mathbf{1 b}$ for only 10 minutes (Fig. 7 and Fig. S27, ESI $\dagger$ ), their green fluorescence was observed in the cytoplasm of MCF-7. Both 1a and 1b quickly entered cells and exhibited unexpectedly biocompatible capability. MTT assay as a standard cell viability protocol was then used to study their cytotoxic effects on MCF-7 cells (Fig. S28 and S29, ESI $\dagger$ ). A high cell viability was observed with a survival rate of above $85 \%$ (in $1.0 \times 10^{4}$ cells per well) after treating MCF-7 cells with dye $1 \mathrm{a}$ or $1 \mathrm{~b}(0-10 \mu \mathrm{M})$ for $24 \mathrm{~h}$. This low cytotoxicity makes these novel dyes applicable for in vitro intracellular imaging.

\subsection{Viscosity determination in real-time during apoptosis}

Considering the perfect correlation of the fluorescence lifetimes of these meso-2-ketopyrrolyl BODIPYs with the viscosity of media, we further investigated the performance of $\mathbf{1 a}$ and $\mathbf{1 b}$ as FMRs in monitoring the viscosity changes during the pathological processes such as cell apoptosis events. Therefore, etoposide, a clinical antitumor drug that induces cell apoptosis by inhibiting the repair of damaged DNA, was used to stimulate MCF-7 cells. The FLIM image of these cells revealed that the fluorescence lifetime of 1a in cytoplasm changed from 2.45 ns to $3.8 \mathrm{~ns}$ during the 60 minutes of etoposide treatment (Fig. 8 and Fig. S30, ESI $\dagger$ ). The average viscosity of the cytoplasm around 1a significantly
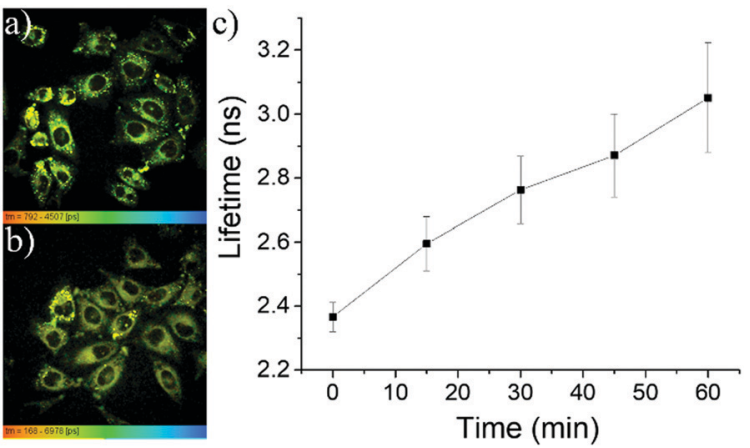

Fig. 8 ( $a$ and b) FLIM images of MCF-7 cells incubated with etoposide for 0 and $45 \mathrm{~min}$, respectively. (c) Variation of the fluorescence lifetimes of $1 \mathrm{a}$ with the extension of the cell apoptosis time. 
a)
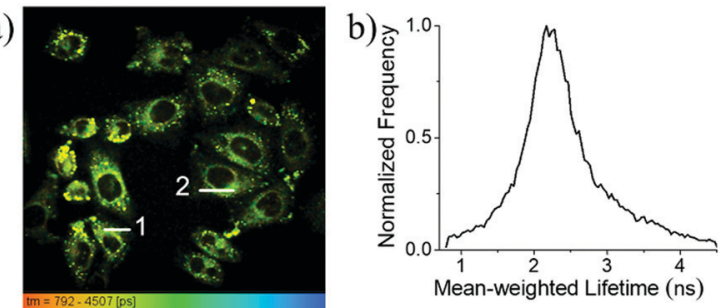

c)

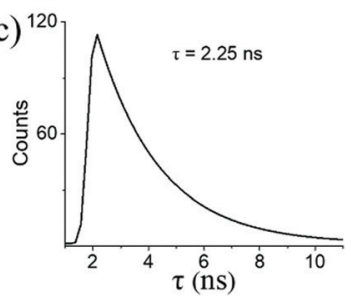

d)

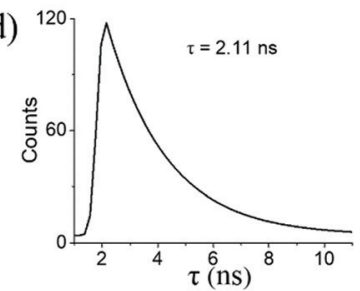

Fig. 9 (a) Intracellular FLIM of 1a (MCF-7 cells, the mean-weighted lifetime range is $0.80-4.50 \mathrm{~ns})$. (b) Histogram showing the fluorescence lifetime distribution ( $x$ axis: the lifetime and $y$ axis: normalized fequency of the black cross point). (c) and (d) Fluorescence lifetimes of regions 1 (c) and 2 (d) marked in (a).

increased from $70 \mathrm{cP}$ to $300 \mathrm{cP}$ and a quite similar linear lifetimeviscosity relationship during cell apoptosis (Fig. 8c) was obtained. The linear correlation of $\mathbf{1 b}$ (Fig. S31, ESI $\dagger$ ) seems to be slightly lost. This might be ascribed to the relatively weak lipotropism and poor solubility compared to those of $\mathbf{1 a}$.

In combination with FLIM, $\mathbf{1 a}$ is a reliable tool for the determination of the local intracellular viscosity. As shown in the FLIM images of MCF-7 cells (Fig. 9a), the fluorescence lifetime of 1a within cells can be clearly mapped from its fluorescence lifetime distribution histogram. For example, the average fluorescence lifetime was established to be $2.4 \mathrm{~ns}$ for 1a (Fig. 9b). This indicates that inside cytoplasm, the average viscosity around $\mathbf{1 a}$ is about $60 \mathrm{cP}$ as shown in the calibration graph (Fig. 6d). The high spatial resolution of these FLIM images was found to be compatible with their corresponding confocal images. This makes it feasible to indicate the local viscosities in different areas of cytoplasm based on the determination of their fluorescence lifetimes. For example, within different randomly chosen intracellular regions, the precision of the resultant fluorescence decay curves is almost identical to those obtained in the solution state. As shown in Fig. 9c and d, the different regions (Fig. 9a) of cells have different lifetimes of $2.25 \mathrm{~ns}$ and $2.11 \mathrm{~ns}$, with respect to 50.9 and $41.0 \mathrm{cP}$, respectively, indicating that the change in intracellular viscosity could be facilely detected by our meso-2-ketopyrrolyl derived BODIPY 1a.

\section{Conclusions}

In summary, we have first synthesized a novel family of unconventional meso-2-ketopyrrolyl BODIPYs via the efficient condensation reactions between oxalyl chloride and substituted pyrrolic derivatives. The meso-2-ketopyrrolyl BODIPYs exhibited high red fluorescence quantum yields of up to $25 \%$ from 620 to $661 \mathrm{~nm}$, and notable AIE-active and viscosity-sensitive characteristics. The formed nanoaggregates were observed to exhibit

morphological distinctions with average diameters owing to different substituents. In addition, the restriction of the rotation of the meso-ketopyrrolyl group in viscous media resulted in large fluorescence enhancement and lengthened the fluorescence lifetime from 0.8 to $3.9 \mathrm{~ns}$, which are in good correlation with the variation of the viscosity in the media. More importantly, as novel mapping viscosity BODIPY indicators, they show excellent applicability for real-time tracking viscosity changes during cell apoptosis events, and for monitoring normal and abnormal cell viscosities and for further quantifying the local viscosity within the living cell. This easy strategy and a perfect linear relationship between the fluorescence lifetime and viscosity might indicate that the developed meso-2-ketopyrrolyl derived BODIPYs here are suitable viscosimeters as designed.

\section{Experimental}

\section{General methods}

Reagents and solvents were used as received from commercial suppliers unless noted otherwise. All reactions were performed in oven-dried or flame-dried glassware, and monitored by TLC using $0.25 \mathrm{~mm}$ silica gel plates with a UV indicator. ${ }^{1} \mathrm{H}$ and ${ }^{13} \mathrm{C}$ NMR were recorded on a $300 \mathrm{MHz}$ NMR spectrometer at room temperature. Chemical shifts $(\delta)$ are given relative to $\mathrm{CDCl}_{3}$ (7.26 ppm for ${ }^{1} \mathrm{H}$ and $77 \mathrm{ppm}$ for ${ }^{13} \mathrm{C}$ ) or internal tetramethylsilane (abbreviated as TMS). High-resolution mass spectra (HRMS) were obtained using APCI-TOF in a positive mode.

\section{Syntheses of meso-2-ketopyrrolyl BODIPYs 1a and b}

Synthesis of 1a. 3-Ethyl-2,4-methylpyrrole (0.95 mL, $7 \mathrm{mmol})$ was dissolved into $60 \mathrm{~mL}$ freshly distilled 1,2-dichloroethane under argon. To this solution was dropwise added oxalyl chloride $(0.17 \mathrm{~mL}, 2 \mathrm{mmol})$ in 1,2-dichloroethane $(10 \mathrm{~mL})$ via a pressure-equalizing dropping funnel under ice-bath conditions. By increasing the reaction temperature to $35{ }^{\circ} \mathrm{C}$, the reaction mixture was then allowed to stir at this temperature for $3 \mathrm{~h}$. To this reaction mixture was added $\mathrm{Et}_{3} \mathrm{~N}(2 \mathrm{~mL})$ under ice-bath conditions. The mixture was further stirred for 10 minutes before subsequent addition of $\mathrm{BF}_{3} \cdot \mathrm{OEt}_{2}(3 \mathrm{~mL})$ at this temperature via a syringe. The reaction mixture was left stirring overnight under refluxing conditions. The reaction mixture was cooled down to room temperature, poured into water $(150 \mathrm{~mL})$ and extracted with dichloromethane $(3 \times 40 \mathrm{~mL})$. Organic layers were combined, and subsequently washed with water. The resultant organic layers were dried over anhydrous sodium sulfate and filtered, and the solvent was evaporated under vacuum. The crude product was then purified by silica gel chromatography (petroleum/ethyl acetate $=4 / 1, \mathrm{v} / \mathrm{v}$ ). Target 1a was obtained as a reddish powder in $18 \%$ yield $(163 \mathrm{mg})$. ${ }^{1} \mathrm{H}$ NMR (300 MHz, $\mathrm{CDCl}_{3}$ ) $\delta: 9.49$ (brs, $\left.1 \mathrm{H} ; \mathrm{NH}\right), 2.52\left(\mathrm{~s}, 6 \mathrm{H} ; \mathrm{CH}_{3}\right.$ ), 2.36-2.28 (m, 9H; $\left.\mathrm{CH}_{2}, \mathrm{CH}_{3}\right), 1.86\left(\mathrm{~s}, 9 \mathrm{H} ; \mathrm{CH}_{3}\right), 1.00(\mathrm{t}, J=7.2 \mathrm{~Hz}$, $\left.9 \mathrm{H} ; \mathrm{CH}_{3}\right) .{ }^{13} \mathrm{C} \mathrm{NMR}\left(75 \mathrm{MHz}, \mathrm{CDCl}_{3}\right) \delta: 179.2,154.8,136.9,136.7$, 136.3, 132.7, 130.5, 128.4, 128.2, 126.1, 17.1, 15.2, 14.7, 12.7, 11.9, 11.1, 11.0, 10.6. HRMS (APCI): $m / z=454.2831[\mathrm{M}+\mathrm{H}]^{+}$.

Synthesis of $\mathbf{1 b}$. As described in the procedure for $\mathbf{1 a}$ above, BODIPY 1b was prepared as a reddish powder in $23 \%$ yield 
(169 mg) from 2,4-methylpyrrole $(0.73 \mathrm{~mL}, 7 \mathrm{mmol}$ ) and oxalyl chloride (0.17 mL, $2 \mathrm{mmol}) .{ }^{1} \mathrm{H} \mathrm{NMR}\left(300 \mathrm{MHz} \mathrm{CDCl}_{3}\right) \delta: 9.39$ (brs, 1H; NH), $6.01(\mathrm{~s}, 2 \mathrm{H}), 5.84(\mathrm{~s}, 1 \mathrm{H}), 2.54\left(\mathrm{~s}, 6 \mathrm{H} ; \mathrm{CH}_{3}\right), 2.32$ $\left(\mathrm{s}, 3 \mathrm{H} ; \mathrm{CH}_{3}\right), 1.95\left(\mathrm{~s}, 6 \mathrm{H} ; \mathrm{CH}_{3}\right), 1.93\left(\mathrm{~s}, 3 \mathrm{H} ; \mathrm{CH}_{3}\right) .{ }^{13} \mathrm{C} \mathrm{NMR}$ $\left(75 \mathrm{MHz}, \mathrm{CDCl}_{3}\right) \delta: 178.9,156.8,141.6,138.7,137.8,133.3$, 129.1, 128.7, 121.0, 113.8, 14.8, 13.6, 13.4, 13.0. HRMS (APCI): $m / z=370.1907[\mathrm{M}+\mathrm{H}]^{+}$.

\section{General synthetic procedure for 1a-d}

To a dried flask containing dipyrrolediketone $2(1 \mathrm{mmol})$ in dichloromethane $(60 \mathrm{~mL})$ was added $0.2 \mathrm{~mL} \mathrm{BF}_{3} \cdot \mathrm{OEt}_{2}$. The solution turned brown quickly. Then 2,4-dimethylpyrrole or 2,4dimethyl-3-ethylpyrrole (1.2 mmol, 1.2 equivalents) in $10 \mathrm{~mL}$ dichloromethane was dropwise added slowly. The mixture was stirred for 3 hours at room temperature $\left(35^{\circ} \mathrm{C}\right)$. When dipyrrolediketone 2 was consumed completely, $3 \mathrm{~mL}$ of $\mathrm{Et}_{3} \mathrm{~N}$ was added and the mixture was stirred for 10 minutes before subsequent addition of $\mathrm{BF}_{3} \cdot \mathrm{OEt}_{2}(3.5 \mathrm{~mL})$ through a syringe. The reaction mixture was left stirring for $30 \mathrm{~min}$. Then the reaction mixture was extracted with EtOAc $(30 \mathrm{~mL} \times 3)$. The organic layers were combined, dried over anhydrous $\mathrm{Na}_{2} \mathrm{SO}_{4}$, filtered, and evaporated to dryness under vacuum. The crude product was purified by column chromatography on silica gel (hexane/EtOAc $=4 / 1, \mathrm{v} / \mathrm{v}$ ) and was further recrystallized from hexane to give $\mathbf{1 a}-\mathbf{d}$ as reddish powders.

1a. It was prepared using the above procedure from 2 a (240 mg, $0.8 \mathrm{mmol}$ ) and 2,4-dimethyl-3-ethylpyrrole (1.2 eq.), affording a reddish powder in $45 \%$ yield $(164 \mathrm{mg}) .{ }^{1} \mathrm{H}$ NMR $(300 \mathrm{MHz}$, $\mathrm{CDCl}_{3}$ ) $\delta: 9.49$ (brs, $\left.1 \mathrm{H} ; \mathrm{NH}\right), 2.52\left(\mathrm{~s}, 6 \mathrm{H} ; \mathrm{CH}_{3}\right), 2.36-2.28(\mathrm{~m}, 9 \mathrm{H}$; $\left.\mathrm{CH}_{2}, \mathrm{CH}_{3}\right), 1.86\left(\mathrm{~s}, 9 \mathrm{H} ; \mathrm{CH}_{3}\right), 1.00\left(\mathrm{t}, J=7.2 \mathrm{~Hz}, 9 \mathrm{H} ; \mathrm{CH}_{3}\right) .{ }^{13} \mathrm{C} \mathrm{NMR}$ $\left(75 \mathrm{MHz}, \mathrm{CDCl}_{3}\right.$ ) $\delta:$ 179.2, 154.8, 136.9, 136.7, 136.3, 132.7, 130.5, $128.4,128.2,126.1,17.1,15.2,14.7,12.7,11.9,11.1,11.0,10.6$. HRMS (APCI): $m / z=454.2831[\mathrm{M}+\mathrm{H}]^{+}$.

1b. It was prepared using the above procedure from $\mathbf{2 b}$ (195 mg, $0.8 \mathrm{mmol}$ ) and 2,4-dimethylpyrrole (1.2 eq.), affording a reddish powder in $32 \%$ yield (94 mg). ${ }^{1} \mathrm{H}$ NMR $(300 \mathrm{MHz}$, $\mathrm{CDCl}_{3}$ ) $\delta: 9.39$ (brs, 1H; NH), 6.01 (s, 2H), $5.84(\mathrm{~s}, 1 \mathrm{H}), 2.54$ (s, $\left.6 \mathrm{H} ; \mathrm{CH}_{3}\right), 2.32\left(\mathrm{~s}, 3 \mathrm{H} ; \mathrm{CH}_{3}\right), 1.95\left(\mathrm{~s}, 6 \mathrm{H} ; \mathrm{CH}_{3}\right), 1.93\left(\mathrm{~s}, 3 \mathrm{H} ; \mathrm{CH}_{3}\right)$. ${ }^{13} \mathrm{C}$ NMR (75 MHz, $\mathrm{CDCl}_{3}$ ) $\delta: 178.9,156.8,141.6,138.7,137.8$, 133.3, 129.1, 128.7, 121.0, 113.8, 14.8, 13.6, 13.4, 13.0. HRMS (APCI): $m / z=370.1907[\mathrm{M}+\mathrm{H}]^{+}$.

1c. It was prepared using the above procedure from 2 a (240 mg, $0.8 \mathrm{mmol}$ ) and 2,4-dimethylpyrrole (1.2 eq.), affording a reddish powder in $45 \%$ yield $(153 \mathrm{mg}) .{ }^{1} \mathrm{H}$ NMR $(300 \mathrm{MHz}$, $\left.\mathrm{CDCl}_{3}\right) \delta: 9.36(\mathrm{~s}, 1 \mathrm{H}), 5.96(\mathrm{~s}, 1 \mathrm{H}), 2.53(\mathrm{~s}, 6 \mathrm{H}), 2.32-2.35(\mathrm{~m}$, $4 \mathrm{H}), 2.28(\mathrm{~s}, 3 \mathrm{H}), 1.92(\mathrm{~s}, 3 \mathrm{H}), 1.88(\mathrm{~s}, 3 \mathrm{H}), 1.88(\mathrm{~s}, 3 \mathrm{H}), 0.98-$ 1.03 (m, 6H). ${ }^{13} \mathrm{C}$ NMR (75 MHz, $\mathrm{CDCl}_{3}$ ) $\delta: 178.6,156.7,154.9$, $140.4,137.9$, 137.5, 136.9, 133.5, 130.6, 129.0, 128.6, 128.0, $126.2,120.2$, 17.1, 16.9, 15.2, 14.6, 13.6, 12.9, 11.9, 11.1, 10.6. HRMS (APCI): $m / z=426.2522[\mathrm{M}+\mathrm{H}]^{+}$.

1d. It was prepared using the above procedure from $\mathbf{2 b}$ (195 mg, $0.8 \mathrm{mmol}$ ) and 2,4-dimethyl-3-ethylpyrrole (1.2 eq.), affording a reddish powder in $41 \%$ yield $(130 \mathrm{mg}) .{ }^{1} \mathrm{H}$ NMR $\left(300 \mathrm{MHz}, \mathrm{CDCl}_{3}\right) \delta: 9.76(\mathrm{~s}, 1 \mathrm{H}), 5.96(\mathrm{~s}, 1 \mathrm{H}), 5.84(\mathrm{~s}, 1 \mathrm{H}), 2.53$ (s, 6H), $2.32(\mathrm{~s}, 5 \mathrm{H}), 1.93(\mathrm{~s}, 6 \mathrm{H}), 1.89(\mathrm{~s}, 3 \mathrm{H}), 1.00(\mathrm{~s}, 3 \mathrm{H})$. ${ }^{13} \mathrm{C}$ NMR (75 $\left.\mathrm{MHz}, \mathrm{CDCl}_{3}\right) \delta: 179.2,156.8,155.0,140.3$, $139.7,137.7,137.1,133.7,133.6$, 129.0, 128.8, 120.3, 113.8,
113.6, 17.1, 14.6, 13.5, 13.4, 13.2, 12.9, 11.0. HRMS (APCI): $m / z=398.2208[\mathrm{M}+\mathrm{H}]^{+}$.

\section{Photophysical characterization}

UV-visible absorption and fluorescence emission spectra were recorded on commercial spectrophotometers (190-870 nm scan range, Shimadzu UV-2450 and Hitachi F-4500) at room temperature ( $1 \mathrm{~cm}$ quartz cuvette). The absolute fluorescence quantum efficiencies in different organic solvents (excited at $500 \mathrm{~nm}$ for 1a, excited at $480 \mathrm{~nm}$ for $\mathbf{1 b}-\mathbf{d}$ ) and the powder state (excited at $550 \mathrm{~nm}$ for $1 \mathbf{a}$ and $500 \mathrm{~nm}$ for $\mathbf{1 b}-\mathbf{d}$ ) of the meso-2-ketopyrrolyl derived BODIPYs 1a-d were obtained using an Edinburgh FLS 920 fluorescence spectrometer by comparing the areas under the corrected emission spectrum of the test sample using an integrating sphere according to the definition of fluorescence efficiency, ${ }^{21}$ using eqn (1) given below:

$$
\Phi_{\mathrm{F}}=\frac{N_{\mathrm{em}}}{N_{\mathrm{abs}}}=\frac{\alpha \int \frac{\lambda}{h c} I_{\mathrm{em}}(\lambda) \mathrm{d} \lambda}{\alpha \int \frac{\lambda}{h c}\left[I_{\mathrm{ex}}(\lambda)-I_{\mathrm{ex}}{ }^{\prime}(\lambda)\right] \mathrm{d} \lambda}
$$

where $N_{\mathrm{em}}$ and $N_{\mathrm{abs}}$ are the numbers of emitted and absorbed photons, respectively, $\alpha$ is the calibration factor for the measurement setup, $\lambda$ is the wavelength, $h$ is Planck's constant, $c$ is the speed of light, $I_{\mathrm{em}}(\lambda)$ is the emission intensity at $\lambda$, and $I_{\mathrm{ex}}(\lambda)$ and $I_{\mathrm{ex}}{ }^{\prime}(\lambda)$ are the intensities of the excitation laser beam with $\lambda$ in the absence and presence of the sample, respectively. The measured $\Phi_{\mathrm{F}}$ value is independent of the shape and thickness of the sample and the power of the excitation laser.

The fluorescence lifetime $(\tau)$ was measured by a timecorrelated single photon counting method using an Edinburgh FLS 980 fluorescence spectrometer and emission was monitored at the peak maximum (excited at $470 \mathrm{~nm}$ ). The fluorescence lifetime values were obtained from deconvolution and distribution lifetime analysis. The solvents were obtained by mixing methanol and glycerol in different proportions. The viscosity values were referenced to previously reported articles. ${ }^{10}$

\section{Crystals suitable for X-ray crystallographic analysis}

CCDC 1541729 (1a), CCDC 1541728 (1b) and CCDC 1901461 (1c) $\dagger$ contain the supplementary crystallographic data for this paper. Diffraction data were collected using a Bruker APEXII CCD area detector diffractometer using graphite-monochromated Mo$\mathrm{K} \alpha$ radiation $(\lambda=0.71073 \AA)$ at $293(2) \mathrm{K}$, with $\phi$ and $\omega$ scan techniques. An empirical absorption correction was applied with the SADABS program. Using Olex $2^{22 a}$ or SHELXL- $97,{ }^{22 b}$ the structure was solved with the ShelXT ${ }^{23}$ structure solution program using direct methods and refined with the ShelXL ${ }^{24}$ refinement package using least squares minimisation. The hydrogen atom coordinates were calculated with SHELXL by using an appropriate riding model with varied thermal parameters. The residual electron densities were of no chemical significance.

\section{DFT computations}

The ground state geometry was optimized by using the DFT method at the B3LYP/6-31+G(d,p) level. The same method was 
used for vibrational analysis to verify that the optimized structures correspond to local minima on the energy surface. TD-DFT computations were used to obtain the vertical excitation energies and oscillator strengths for the optimized ground state equilibrium geometries at the B3LYP/6-31+G(d, p) theoretical level. TD-DFT calculations of 1a in dichloromethane were done using the SelfConsistent Reaction Field method and Polarizable Continuum Model.

\section{Cell culture}

MCF-7 cells were obtained from the Institute of Basic Medical Sciences (IBMS) of the Chinese Academy of Medical Sciences (CAMS). All cell lines were maintained under standard culture conditions (an atmosphere of $5 \% \mathrm{CO}_{2}$ and $95 \%$ air at $37{ }^{\circ} \mathrm{C}$ ) in DMEM, supplemented with 10\% FBS (fetal bovine serum). The cells were used in the exponential phase of growth on $35 \mathrm{~mm}$ glass bottom culture dishes for $24 \mathrm{~h}$. The cells were treated with $5 \mu \mathrm{M}$ of $\mathbf{1 a}$ and $\mathbf{1 b}$ in culture media for $10 \mathrm{~min}$ at $37{ }^{\circ} \mathrm{C}$ with $5 \%$ $\mathrm{CO}_{2}$ in a humidified incubator. Fluorescence imaging was then carried out after washing the cells with PBS. For the control experiment, the cells without treatment of dyes did not show any noticeable fluorescence under the same conditions.

\section{Cytotoxicity study}

MCF-7 cells $\left(10^{6}\right.$ cells $\left.\mathrm{mL}^{-1}\right)$ were dispersed within replicate 96-well microtiter plates to a total volume of $200 \mu \mathrm{L}$ well ${ }^{-1}$. Plates were maintained at $37{ }^{\circ} \mathrm{C}$ in a $5 \% \mathrm{CO}_{2}$ and $95 \%$ air incubator for 4-6 h. Then MCF-7 cells were incubated for $24 \mathrm{~h}$ with different concentrations of $\mathbf{1 a}$ and $\mathbf{1 b}$. MTT solution was then added to each well. After $4 \mathrm{~h}$, the remaining MTT solution was removed, and $150 \mu \mathrm{L}$ of DMSO was added to each well to dissolve formazan crystals. Absorbance was measured at $490 \mathrm{~nm}$ in a Triturus microplate reader.

\section{Viscosity determination in real-time during apoptosis}

The fluorescence lifetimes of 1a under different conditions were obtained with an excitation wavelength of $515 \mathrm{~nm}$ and collected at 520-600 $\mathrm{nm}$. The fluorescence lifetimes of $\mathbf{1 b}$ under different conditions were obtained with an excitation wavelength of $488 \mathrm{~nm}$ and collected at 510-600 nm. MCF-7 cells internalized with $\mathbf{1 a}$ and $\mathbf{1 b}$ were washed with PBS and then etoposide was added. ${ }^{11}$ Fluorescence images were obtained at different time points: $0,5,15,30,45$, and $60 \mathrm{~min}$.

\section{Conflicts of interest}

There are no conflicts to declare.

\section{Acknowledgements}

This work was supported by the National Natural Science Foundation of China (Grant No. 21672006, 21672007, 21402001 and 21871006), Hong Kong Polytechnic University (1-YW2T and 1-ZE1C), the Hong Kong Research Grants Council (C6009-17G), the Open Funds of Nanjing University State Key Laboratory of
Coordination Chemistry (SKLCC1911), and the Doctoral up Starting Foundation of Anhui Normal University (2017XJJ28).

\section{References}

1 (a) S. J. Singer and G. L. Nicolson, Science, 1972, 175, 720-731; (b) S. Chen, Y. Hong, Y. Zeng, Q. Sun, Y. Liu, E. Zhao, G. Bai, J. Qu, J. Hao and B. Z. Tang, Chem. - Eur. J., 2015, 21, 4315-4320; (c) P. Ning, P. Dong, Q. Geng, L. Bai, X. Tian, R. Shao, L. Li and X. Meng, J. Mater. Chem. B, 2017, 5, 2743-2749; (d) Y. He, J. Shin, W. Gong, P. Das, J. Qu, Z. Yang, W. Liu, C. Kang, J. Qu and J. S. Kim, Chem. Commun., 2019, 55, 2453-2456.

2 (a) M. K. Kuimova, S. W. Botchway, A. W. Parker, M. Balaz, H. A. Collins, H. L. Anderson, K. Suhling and P. R. Ogilby, Nat. Chem., 2009, 1, 69-73; (b) M. K. Kuimova, Phys. Chem. Chem. Phys., 2012, 14, 12671-12686; (c) X. Qian and Z. Xu, Chem. Soc. Rev., 2015, 44, 4487-4493; (d) F. Liu, T. Wu, J. Cao, S. Cui, Z. Yang, X. Qiang, S. Sun, F. Song, J. Fan, J. Wang and X. Peng, Chem. - Eur. J., 2013, 19, 1548-1553; (e) H. Doan, S. L. Raut, D. Yale, M. Balaz, S. V. Dzyuba and Z. Gryczynski, Chem. Commun., 2016, 52, 9510-9513; $(f)$ W. Chen, C. Gao, X. Liu, F. Liu, F. Wang, L. Tang and J.-H. Jiang, Anal. Chem., 2018, 90, 8736-8741.

3 (a) M. R. Dent, I. Lopez-Duarte, C. J. Dickson, P. Chairatana, H. L. Anderson, I. R. Gould, D. Wylie, A. Vyšniauskas, N. J. Brooks and M. K. Kuimova, Chem. Commun., 2016, 52, 13269-13272; (b) S.-C. Lee, J. Heo, J.-W. Ryu, C.-L. Lee, S. Kim, J.-S. Tae, B.-O. Rhee, S.-W. Kim and O.-P. Kwon, Chem. Commun., 2016, 52, 13695-13698; (c) T. Luo, Y. Lu, S. Liu, D. Lin and J. Qu, Anal. Chem., 2017, 89, 8104-8111; (d) M. Ren, B. Deng, K. Zhou, X. Kong, J.-Y. Wang and W. Lin, Anal. Chem., 2017, 89, 552-555; (e) L. Hou, P. Ning, Y. Feng, Y. Ding, L. Bai, L. Li, H. Yu and X. Meng, Anal. Chem., 2018, 90, 7122-7126.

4 (a) G. S. Zubenko, U. Kopp, T. Seto and L. L. Firestone, Psychopharmacology, 1999, 145, 175-180; (b) H. Tan, Y. Qiu, H. Sun, J. Yan and L. Zhang, Chem. Commun., 2019, 55, 2688-2691.

5 (a) A. Loudet and K. Burgess, Chem. Rev., 2007, 107, 4891-4932; (b) G. Ulrich, R. Ziessel and A. Harriman, Angew. Chem., Int. Ed., 2008, 47, 1184-1201; (c) N. Boens, V. Leen and W. Dehaen, Chem. Soc. Rev., 2012, 41, 1130-1172; (d) H. Lu, J. Mack, Y. Yang and Z. Shen, Chem. Soc. Rev., 2014, 43, 4778-4823; (e) Y. Ni and J. Wu, Org. Biomol. Chem., 2014, 12, 3774-3791; $(f)$ N. Boens, B. Verbelen and W. Dehaen, Eur. J. Org. Chem., 2015, 6577-6595.

6 (a) M. K. Kuimova, G. Yahioglu, J. A. Levitt and K. Suhling, J. Am. Chem. Soc., 2008, 130, 6672-6673; (b) N. A. Hosny, G. Mohamedi, P. Rademeyer, J. Owen, Y. L. Wu, M. X. Tang, R. J. Eckersley, E. Stride and M. K. Kuimova, Proc. Natl. Acad. Sci. U. S. A., 2013, 110, 9225-9230; (c) I. López-Duarte, T. T. Vu, M. A. Izquierdo, J. A. Bull and M. K. Kuimova, Chem. Commun., 2014, 50, 5282-5284; (d) A. Vyšniauskas, M. Qurashi, N. Gallop, M. Balaz, H. L. Andersonb and M. K. Kuimova, Chem. Sci., 2015, 6, 5773-5778; (e) T. T. Vu, 
R. Méallet-Renaul, G. Clavier, B. A. Trofimov and M. K. Kuimova, J. Mater. Chem. C, 2016, 4, 2828-2833; ( $f$ ) P. S. Sherin, I. López-Duarte, M. R. Dent, M. Kubánková, A. Vyšniauskas, J. A. Bull, E. S. Reshetnikova, A. S. Klymchenko, Y. P. Tsentalovich and M. K. Kuimova, Chem. Sci., 2017, 8, 3523-3528; (g) J. E. Chambers, M. Kubánková, R. G. Huber, I. López-Duarte, E. Avezov, P. J. Bond, S. J. Marciniak and M. K. Kuimova, ACS Nano, 2018, 12, 4398-4407.

7 (a) M. A. H. Alamiry, A. C. Benniston, G. Copley, K. J. Elliott, A. Harriman, B. Stewart and Y.-G. Zhi, Chem. Mater., 2008, 20, 4024-4032; (b) S. Raut, J. Kimball, R. Fudala, H. Doan, B. Maliwal, N. Sabnis, A. Lacko, I. Gryczynski, S. V. Dzyuba and Z. Gryczynski, Phys. Chem. Chem. Phys., 2014, 16, 27037-27042; (c) S. L. Raut, J. D. Kimball, R. Fudala, I. Bora, R. Chib, H. Jaafari, M. K. Castillo, N. W. Smith, I. Gryczynski, S. V. Dzyuba and Z. Gryczynski, Phys. Chem. Chem. Phys., 2016, 18, 4535-4540; (d) L.-L. Li, K. Li, M.-Y. Li, L. Shi, Y.-H. Liu, H. Zhang, S.-L. Pan, N. Wang, Q. Zhou and X.-Q. Yu, Anal. Chem., 2018, 90, 5873-5878.

8 (a) Z. Yang, Y. He, J.-H. Lee, N. Park, M. Suh, W.-S. Chae, J. Cao, X. Peng, H. Jung, C. Kang and J. S. Kim, J. Am. Chem. Soc., 2013, 135, 9181-9185; (b) Z. Yang, Y. He, J. H. Lee, W.-S. Chae, W. X. Ren, J. H. Lee, C. Kang and J. S. Kim, Chem. Commun., 2014, 50, 11672-11675; (c) H. Lee, Z. Yang, Y. Wi, T. W. Kim, P. Verwilst, Y. H. Lee, G. Han, C. Kang and J. S. Kim, Bioconjugate Chem., 2015, 26, 2474-2480; (d) D. Dziuba, P. Jurkiewicz, M. Cebecauer, M. Hof and M. Hocek, Angew. Chem., Int. Ed., 2016, 55, 174-178; (e) W. Zhang, W. Sheng, C. Yu, Y. Wei, H. Wang, E. Hao and L. Jiao, Chem. Commun., 2017, 53, 5318-5321.

9 (a) H. L. Kee, C. Kirmaier, L. Yu, P. Thamyongkit, W. J. Youngblood, M. E. Calder, L. Ramos, B. C. Noll, D. F. Bocian, W. R. Scheidt, R. R. Birge, J. S. Lindsey and D. Holten, J. Phys. Chem. B, 2005, 109, 20433-20443; (b) E. Bahaidarah, A. Harriman, P. Stachelek, S. Rihn, E. Heyer and R. Ziessel, Photochem. Photobiol. Sci., 2014, 13, 1397-1401.

10 L. Wang, Y. Xiao, W. Tian and L. Deng, J. Am. Chem. Soc., 2013, 135, 2903-2906.

11 H. Zhu, J. Fan, M. Li, J. Cao, J. Wang and X. Peng, Chem. Eur. J., 2014, 20, 4691-4696.

12 R. Guliyev, S. Ozturk, E. Sahin and E. U. Akkaya, Org. Lett., 2012, 14, 1528-1531.

13 C. Yu, E. Hao, T. Li, J. Wang, W. Sheng, Y. Wei, X. Mu and L. Jiao, Dalton Trans., 2015, 44, 13897-13905.

14 (a) Y. Ni, L. Zeng, N.-Y. Kang, K.-W. Huang, L. Wang, Z. Zeng, Y.-T. Chang and J. Wu, Chem. - Eur. J., 2014, 20, 2301-2310; (b) S. Kim, J. Bouffard and Y. Kim, Chem. - Eur. J., 2015, 21, 17459-17465; (c) Y. Ni, R. K. Kannadorai, S. W.-K. Yu, Y.-T. Chang and J. Wu, Org. Biomol. Chem., 2017, 15, 4531-4535; (d) T.-I. Kim, H. Kim, Y. Choi and Y. Kim, Sens. Actuators, B, 2017, 249, 229-234; (e) T.-I. Kim, B. Hwang, B. Lee, J. Bae and Y. Kim, J. Am. Chem. Soc., 2018, 140, 11771-11776; $(f)$ J. A. Peterson, C. Wijesooriya, E. J. Gehrmann, K. M. Mahoney, P. P. Goswami, T. R. Albright, A. Syed, A. S. Dutton, E. A. Smith and A. H. Winter, J. Am. Chem. Soc., 2018, 140, 7343-7346.
15 (a) N. Zhao, M. G. Vicente, F. R. Fronczek and K. M. Smith, Chem. - Eur. J., 2015, 21, 6181-6192; (b) N. Zhao, S. Xuan, Z. Zhou, F. R. Fronczek, K. M. Smith and M. G. H. Vicente, J. Org. Chem., 2017, 82, 9744-9750; (c) N. Zhao, T. M. Williams, Z. Zhou, F. R. Fronczek, M. Sibrian-Vazquez, S. D. Jois and M. G. H. Vicente, Bioconjugate Chem., 2017, 28, 1566-1579; (d) G. Zhang, N. Zhao, P. BobadovaParvanova, M. Wang, F. R. Fronczek, K. M. Smith and M. G. H. Vicente, J. Phys. Chem. A, 2018, 122, 6256-6265; (e) D. J. LaMaster, N. E. M. Kaufman, A. S. Bruner and M. G. H. Vicente, J. Phys. Chem. A, 2018, 122, 6372-6380; $(f)$ C. Duan, Y. Zhou, G.-G. Shan, Y. Chen, W. Zhao, D. Yuan, L. Zeng, X. Huang and G. Niu, J. Mater. Chem. C, 2019, 7, 3471-3478.

16 (a) S. Choi, J. Bouffard and Y. Kim, Chem. Sci., 2014, 5, 751-755; (b) H. Chua, Y. Ni, M. Garai, B. Zheng, K.-W. Huang, Q.-H. Xu, J. Xu and J. Wu, Chem. - Asian J., 2015, 10, 1631-1634.

17 (a) R. Hu, C. F. A. M. Gómez-Durán, J. W. Y. Lam, J. L. Belmonte-Vázquez, C. Deng, S. Chen, R. Ye, E. PeñaCabrera, Y. Zhong, K. S. Wong and B. Z. Tang, Chem. Commun., 2012, 48, 10099-10101; (b) Z. Zhao, B. Chen, J. Geng, Z. Chang, L. Aparicio-Ixta, H. Nie, C. C. Goh, L. G. Ng, A. Qin, G. Ramos-Ortiz, B. Liu and B. Z. Tang, Part. Part. Syst. Charact., 2014, 31, 481-491; (c) C. F. A. Gómez-Durán, R. Hu, G. Feng, T. Li, F. Bu, M. Arseneault, B. Liu, E. PeñaCabrera and B. Z. Tang, ACS Appl. Mater. Interfaces, 2015, 7, 15168-15176; (d) H.-T. Feng, X. Gu, J. W. Y. Lam, Y.-S. Zheng and B. Z. Tang, J. Mater. Chem. C, 2018, 6, 8934-8940.

18 (a) R. S. Singh, R. K. Gupta, R. P. Paitandi, M. Dubey, G. Sharma, B. Koch and D. S. Pandey, Chem. Commun., 2015, 51, 9125-9128; (b) H. T. Feng, J.-B. Xiong, Y.-S. Zheng, B. Pan, C. Zhang, L. Wang and Y. Xie, Chem. Mater., 2015, 27, 7812-7819; (c) H. Manzano, I. Esnal, T. Marqués-Matesanz, J. Bañuelos, I. López-Arbeloa, M. J. Ortiz, L. Cerdán, A. Costela, I. García-Moreno and J. L. Chiara, Adv. Funct. Mater., 2016, 26, 2756-2769; (d) E. Sen, K. Meral and S. Atilgan, Chem. - Eur. J., 2016, 22, 736-745.

19 (a) J. Mei, Y. Hong, J. W. Y. Lam, A. Qin, Y. Tang and B. Z. Tang, Adv. Mater., 2014, 26, 5429-5479; (b) J. Mei, N. L. Leung, R. T. Lam, J. W. Kwok and B. Z. Tang, Chem. Rev., 2015, 115, 11718-11940; (c) M. Chen, X. Hu, J. Liu, B. Li, N. L. C. Leung, L. Viglianti, T. S. Cheung, H. H. Y. Sung, R. T. K. Kwok, I. D. Williams, A. Qin, J. W. Y. Lam and B. Z. Tang, Chem. Sci., 2018, 9, 7829-7834; (d) D. Wang, H. Su, R. T. K. Kwok, X. Hu, H. Zou, Q. Luo, M. M. S. Lee, W. Xu, J. W. Y. Lam and B. Z. Tang, Chem. Sci., 2018, 9, 3685-3693.

20 (a) S. Gan, J. Zhou, T. A. Smith, H. Su, W. Luo, Y. Hong, Z. Zhao and B. Z. Tang, Mater. Chem. Front., 2017, 1, 2554-2558; (b) M. Yamaguchi, S. Ito, A. Hirose, K. Tanaka and Y. Chujo, Mater. Chem. Front., 2017, 1, 1573-1579; (c) J. S. Ni, H. Liu, M. Jiang, Z. Zhao, Y. Chen, R. T. K. Kwok, J. W. Y. Lam, Q. Peng and B. Z. Tang, Mater. Chem. Front., 2018, 2, 1498-1507; (d) F. Ren, P. Liu, Y. Gao, J. Shi, B. Tong, Z. Cai and Y. Dong, Mater. Chem. Front., 2019, 3, 57-63. 
21 Y. Kawamura, H. Sasabe and C. Adachi, Jpn. J. Appl. Phys., 2004, 43, 7729-7730.

22 (a) O. V. Dolomanov, L. J. Bourhis, R. J. Gildea, J. A. K Howard and H. Puschmann, J. Appl. Crystallogr., 2009, 42, 339-341; (b) G. M. Sheldrick, SHELXTL 5.10 for Windows NT:
Structure Determination Software Programs, Bruker Analytical X-ray Systems, Inc., Madison, WI, 1997.

23 G. M. Sheldrick, Acta Crystallogr., Sect. A: Found. Adv., 2015, 71, 3-8. 24 G. M. Sheldrick, Acta Crystallogr., Sect. A: Found. Crystallogr., 2008, 64, 112-122. 